\title{
Design e o ensino da Geometria no Brasil: das Provas de Habilidades Específicas à matriz curricular do curso de Design da Universidade de São Paulo
}

\section{Design and teaching of Geometry in Brazil: from the Specific Ability Tests to the curriculum matrix of the Design course of the University of São Paulo}

\author{
Frederico Braida, Universidade Tecnológica Federal do Paraná; Universidade \\ Federal de Juiz de Fora. \\ frederico.braida@ufjf.edu.br
}

\author{
Rodolfo Eduardo Vertuan, Universidade Tecnológica Federal do Paraná. \\ rodolfovertuan@utfpr.edu.br
}

Rodrigo Manoel Dias Andrade, Universidade Tecnológica Federal do Paraná. rodrigomandrade@utfpr.edu.br

\begin{abstract}
Resumo
Este artigo tem por objetivo principal apresentar uma reflexão sobre as relações entre o campo do Design e o ensino da Geometria, a partir das Provas de Habilidades Específicas para o curso de graduação em Design. Metodologicamente, a partir de uma pesquisa qualitativa, bibliográfica e documental, foi enfocado o conteúdo geométrico nas provas aplicadas pela Universidade de São Paulo (USP) de 2006 a 2016, estabelecendo correlações entre tal conteúdo e a abordagem da Geometria tanto na Base Nacional Comum Curricular quanto nas Diretrizes Curriculares Nacionais para o curso de Design e no Projeto Pedagógico do Curso de Design da USP. Ao final, à guisa de conclusão, pode-se afirmar que as discussões decorrentes das análises empreendidas neste artigo evidenciam a necessidade permanente de se refletir criticamente sobre as habilidades e competências em Geometria demandadas aos ingressantes no curso de Design e contempladas durante a formação no Ensino Superior.
\end{abstract}

Palavras-chave: Geometria, Design, Provas de Habilidades Específicas

\begin{abstract}
The main aim of this paper is to present a reflection about the relations between the field of Design and the teaching of Geometry, from the Specific Ability Tests for the Design undergraduate course. Methodologically, from a qualitative, bibliographical and documentary research, the geometric content was focused on the tests applied by the University of São Paulo (USP) from 2006 to 2016, establishing correlations between such content and the approach of Geometry both in the National Curricular Common Base as well as in the National Curricular Guidelines for the Design course and in the Pedagogical Project of the USP Design Course. At the end, as a conclusion, it can be affirmed that the discussions resulting from the analyzes undertaken in this paper show the permanent need to reflect critically on the skills and competences in Geometry demanded of the students that intent to be a designer and contemplated during the Design undergraduate course.
\end{abstract}

Keywords: Geometry, Design, Specific Ability Tests 


\section{Introdução}

Este artigo aborda o tema da Geometria como componente curricular dos cursos de Design no Brasil, tendo como foco principal a discussão sobre esse conteúdo nas Provas de Habilidades Específicas (PHE). Para tanto, são estabelecidas algumas reflexões sobre a Geometria e sua contribuição para a formação dos designers na contemporaneidade, a partir de uma perspectiva triplamente articulada: (1) como unidade temática na Educação Básica, (2) como conteúdo das PHE e (3) como competência a ser desenvolvida durante os cursos de graduação em Design. Trata-se, portanto, de uma discussão em que o tema da Geometria está presente em três momentos da vida de um designer: (1) na sua formação escolar, (2) no processo seletivo para o ingresso em um curso de graduação e (3) durante a sua formação superior.

De forma mais específica, adota-se como objeto empírico as PHE para o curso de Design da Universidade de São Paulo (USP), campus São Paulo - Capital, aplicadas aos ingressantes do curso de Design de 2006 a 2016. Observa-se que o curso de Design da USP foi iniciado em 2006 e está vinculado à Faculdade de Arquitetura e Urbanismo (FAU) (UNIVERSIDADE DE SÃO PAULO, [s.d.]). A principal questão discutida neste artigo é: Como o conteúdo de Geometria tem sido abordado nos documentos oficiais dos cursos de Design no Brasil, sobretudo levando-se em consideração as PHE FAU USP e o Projeto Pedagógico do Curso de Design da USP (PPC Design USP), e como esse conteúdo dialoga com a Base Nacional Comum Curricular (BNCC) e com as Diretrizes Curriculares Nacionais para o curso de Design (DCND)?

As PHE, também denominadas Testes de Habilidades Específicas (THE) ou Certificação de Habilidades Específicas (CHE) ou, ainda, Provas de Aptidão, são "avaliações adotadas para acesso a determinados cursos de graduação no ensino superior brasileiro" (CERQUEIRA, 2015, p.17). Variando de instituição para instituição, são diversos os cursos, das diferentes áreas do conhecimento humano, que exigem aprovação nesses tipos de avaliação para o ingresso na Educação Superior.

Como o próprio nome da prova sinaliza, supostamente, o objetivo principal de uma PHE é avaliar se os candidatos desenvolveram, ao longo de suas vidas (escolares), na Educação Básica, habilidades específicas requeridas para o início dos estudos mais aprofundados (em nível superior) em um determinado campo do conhecimento. Esse tipo de prova "busca garantir que os estudantes que ingressarem naquele curso sejam realmente capazes de realizar certos procedimentos mínimos que serão necessários para o correto aproveitamento dos ensinamentos" (TESTE..., [s.d.]).

Deve-se destacar que a necessidade da aplicação das PHE não é consensual entre os pesquisadores e professores das diferentes áreas do conhecimento. Também não há um padrão que normatize os conteúdos dessas provas. Somado a essas imprecisões e inconsistências, temse o fato de que a literatura existente sobre as PHE é bastante exígua, o que sinaliza a falta de pesquisas sobre esse tema.

Nesse sentido, as PHE, de uma maneira geral, mostram-se como objetos de investigação relevantes no contexto da avaliação em Educação e, em especial, sobre o ensino do Design, como é o caso das questões abordadas neste artigo. A pesquisa sobre esse tema justifica-se, pois 
há uma grande demanda por evidências que subsidiem as decisões de se aplicar ou não essas provas nos processos seletivos para ingresso de alunos nos cursos superiores, bem como de se definir os seus conteúdos. Além disso, a pesquisa sobre as PHE pode contribuir para uma reflexão sobre os pressupostos das habilidades específicas demandadas pelos cursos de graduação, as quais supostamente devem ser desenvolvidas na Educação Básica (e/ou em atividades extraescolares pregressas).

A despeito da pouca reflexão sistematizada sobre as PHE, observa-se que mais recentemente esse tema tem estado, ainda que em profundidades diferenciadas, nas pautas das discussões pedagógicas das comissões e órgãos colegiados das Instituições de Ensino Superior (IES). Podese destacar dois fatores consideráveis que têm feito as IES se posicionarem e refletirem sobre as PHE: (1) a implantação do Sistema de Seleção Unificada (SISU), um sistema do Ministério da Educação (MEC) por meio do qual IES públicas selecionam candidatos participantes do Exame Nacional do Ensino Médio (Enem) (BRASIL, 2019) e (2) o uso massivo dos computadores como ferramentas de expressão, representação gráfica e criação. Enquanto a introdução dos computadores (da tecnologia digital) nos processos criativos e técnicos questiona as habilidades específicas manuais ou analógicas (predominantes nas PHE), o SISU impede a adesão de cursos que aplicam as PHE.

É nesse cenário que a FAU USP iniciou, em agosto de 2016, um amplo processo de discussão sobre as PHE, por meio de reuniões conjuntas e abertas à comunidade, e de reuniões específicas da Comissão de Graduação (UNIVERSIDADE DE SÃO PAULO, 2017, p.1), publicizando os resultados dos debates e as deliberações no site da faculdade. Também estão disponibilizadas as PHE dos últimos anos, de 2006 a 2016, os quais abarcam todo o período de existência do curso de Design da USP. Portanto, pode-se afirmar que é em função da relevância dessa temática, da qualidade das discussões travadas na FAU USP e da disponibilização das provas para consulta que se configurou o recorte e a seleção dos objetos de análise empírica da pesquisa aqui relatada.

Metodologicamente, este artigo é fruto de uma pesquisa predominantemente qualitativa, alicerçada nas pesquisas bibliográfica e documental. Dentro do escopo das PHE da FAU USP, adotadas como objetos empíricos, as análises recaíram sobre os conteúdos de Geometria, devido à importância que esse campo assume não somente nas PHE, mas também na BNCC e na formação e atuação profissional dos designers. Ainda, de forma mais específica, neste artigo são abordadas, a título de exemplificação, os conteúdos vinculados aos tópicos "concordância e tangência", uma vez que esses tópicos estiveram presentes em todas as provas analisadas.

Portanto, o principal objetivo deste artigo é tecer considerações e uma reflexão crítica sobre a avaliação das competências e habilidades em Geometria por meio das PHE para o curso de Design, a partir de um olhar dialógico que contempla a formação dos designers tanto na Educação Básica quanto no Ensino Superior. Para isso, de forma mais específica, é enfocado o conteúdo da Geometria nas PHE aplicadas pela FAU USP de 2006 a 2016 para o ingresso no curso de Design, estabelecendo correlações entre tal conteúdo e as menções aos saberes geométricos presentes na BNCC, nas DCND e no PPC Design USP. 


\section{Metodologia}

Este artigo é fruto de uma pesquisa predominantemente qualitativa, tanto exploratória quanto descritiva, e é resultado de parte de uma pesquisa de pós-doutorado realizada no Programa de Pós-Graduação em Matemática em Rede Nacional (PROFMAT), na Universidade Tecnológica Federal do Paraná (UTFPR), no câmpus de Toledo, cujo objetivo geral é investigar sobre o ensino na Geometria para alguns cursos de graduação no Brasil, adotando-se uma postura reflexiva e crítica, em diálogo com a formação dos graduandos durante a sua vida estudantil na Educação Básica.

Levando-se em conta os procedimentos de coleta de dados, bem como as fontes consultadas, este artigo é decorrente de uma pesquisa bibliográfica e documental. A revisão de bibliografia incluiu, principalmente, trabalhos científicos e matérias sobre as PHE publicadas em jornais, sites noticiosos e em sites das universidades. A pesquisa documental contemplou a legislação (e suas disposições normativas complementares) que diz respeito à educação brasileira, sobretudo aquela vinculada ao MEC, bem como editais de vestibulares de diversas IES e PHE aplicadas nos últimos anos.

Como objetos empíricos de análise foram selecionadas as PHE da FAU USP aplicadas para o curso de Design, dentre as quais, elegeu-se as Provas de Geometria (e funções), dentro de um recorte temporal que vai desde 2006 a 2016. A escolha desse corpus de pesquisa justifica-se, sobretudo, pela relevância da FAU USP na formação de designers brasileiros. Destaca-se que o curso de Design da USP ocupou o primeiro lugar no Ranking Universitário Folha (RUF) 2018 (FOLHA DE SÃO PAULO, 2018). Além disso, de um ponto de vista pragmático, ressalta-se que a FAU USP disponibiliza, em seu site, todas as provas incluídas no escopo da pesquisa realizada, facilitando o acesso às mesmas por parte de qualquer interessado.

De forma mais específica, foi realizada uma análise de conteúdo (BARDIN, 2011) nas provas pesquisadas, com um foco especial para as questões de construção geométrica, dentre as quais destacaram-se aquelas que abordam os tópicos de concordância e tangência, sobretudo em função de sua recorrência nas provas. Em todas as provas analisadas, ao menos uma das questões diziam respeito às construções geométricas.

A Tabela 1 apresenta as questões que, em cada prova analisada, abordaram o tema da concordância e tangência. Conforme pode-se constatar, em oito das 11 provas, os conteúdos relacionados à concordância e à tangência encontravam-se na primeira questão. Destaca-se que, nas provas dos anos de 2013, 2014 e 2016, as provas eram compostas por apenas duas questões, ainda que elas fossem subdivididas em dois ou mais itens. Nessas provas, uma das questões eram sobre concordância e tangência. Assim, fica comprovada a relevância desse tópico dentro das provas investigadas.

A análise de conteúdo também abrangeu a legislação investigada, vinculada ao MEC, buscando-se identificar como o vocábulo "geometria" e palavras aproximadas (tais como geométrica[s]/o[s]) estão contempladas em tais documentos. 


\begin{tabular}{c|c|c}
\hline Ano da Prova & Total de questões & Questões sobre "concordância e tangência" \\
\hline 2006 & 4 & Questão 1 \\
\hline 2007 & 5 & Questão 1 \\
\hline 2008 & 4 & Questão 1 \\
\hline 2009 & 4 & Questão 2 \\
\hline 2010 & 4 & Questão 3 \\
\hline 2011 & 4 & Questões 1 e 4 \\
\hline 2012 & 4 & Questão 4 \\
\hline 2013 & 2 & Questão 1 \\
\hline 2014 & 2 & Questão 1 \\
\hline 2015 & 4 & Questão 1 \\
\hline 2016 & 2 & Questão 1 \\
\hline
\end{tabular}

Tabela 1: Participação das questões sobre concordância e tangência nas PHE da FAU/USP de 2006 a 2016. Fonte: dos autores.

Ao final, após uma análise comparativa dos tópicos relacionados à Geometria na BNCC, nas DCND, no PPC Design da USP e nas PHE FAU USP, para além da apresentação das considerações que buscam responder à questão principal trazida à baila neste artigo, foram elencadas algumas reflexões, tanto de ordem específica quanto de caráter mais aprofundado, que dizem respeito, inclusive, às políticas públicas sobre o ensino e avaliação da Geometria, bem como às diretrizes curriculares para a formação de designers no Brasil.

\section{O ensino da Geometria no Brasil segundo documentos oficiais do Ministério da Educação: da Educação Básica ao curso superior de Design}

A Geometria é um campo que "envolve o estudo de um amplo conjunto de conceitos e procedimentos necessários para resolver problemas do mundo físico e de diferentes áreas do conhecimento" (BRASIL, [2017], p. 271). É de se destacar que, no texto da "Lei de Diretrizes e Bases da Educação Nacional” (LDB), a Lei n. 9.394, de 20 de dezembro de 1996, não consta a palavra "geometria". Mas, pode-se admitir que a Geometria está contemplada quando se menciona, de maneira geral, o estudo da Matemática, bem como, indiretamente, "o conhecimento do mundo físico" (BRASIL, [2019]). Também deve-se ressaltar que, tal como na LDB, o termo "geometria" não está presente nas "Diretrizes Curriculares Nacionais Gerais da Educação Básica" (BRASIL, 2013).

No âmbito da hierarquia da legislação e dos documentos vinculados ao MEC para a educação brasileira, a palavra geometria se faz presente na BNCC. Na terceira versão da BNCC, o vocábulo "geometria" é mencionado 50 vezes. As variações "geométrica(s)" aparecem nesse documento 55 vezes e as variações "geométrico(s)", 17 vezes. Como pode-se observar, as questões vinculadas à Geometria ganham uma grande importância na BNCC, onde, além de ser considerada um campo da Matemática, está explicitamente presente no campo de experiências "Espaços, tempos, quantidades, relações e transformações" da Educação Infantil - quando é mencionado o "reconhecimento de formas geométricas" (BRASIL, [2017], p. 43) - e é 
entendida como uma das cinco unidades temáticas da área da Matemática do Ensino Fundamental.

Sobre a unidade temática Geometria, a BNCC para a etapa do Ensino Fundamental afirma que "estudar posição e deslocamentos no espaço, formas e relações entre elementos de figuras planas e espaciais pode desenvolver o pensamento geométrico dos alunos" (BRASIL, [2017], p. 271). Por sua vez, no texto da BNCC do Ensino Médio, o radical "geom-" está presente 23 vezes (BRASIL, [2018]).

Cumpre salientar, inclusive, que a Geometria também está consideravelmente contemplada no "Referencial curricular nacional para a educação infantil" (BRASIL, 1998), nos Parâmetros Curriculares Nacionais da Matemática para o Ensino Fundamental (BRASIL, 1997) e para o Ensino Médio (BRASIL, [1999]), especialmente no documento intitulado "PCN Ensino Médio +: orientações educacionais complementares aos Parâmetros Curriculares Nacionais: Ciências da Natureza, Matemática e suas Tecnologias" (BRASIL, [2002]).

Com relação à abordagem da Geometria nas DCND, de acordo com a Resolução n ${ }^{\circ}$ 5, de 8 de março de 2004, da Câmara de Educação Superior (CES), do Conselho Nacional de Educação (CNE) do MEC, a qual "aprova as Diretrizes Curriculares Nacionais do Curso de Graduação em Design e dá outras providências" (BRASIL, 2004), é de se destacar que a palavra não se apresenta de forma explícita. Subtende-se que esse conteúdo está inserido nas questões relativas aos meios de representação e às teorias e história do Design. Deve-se lembrar, por exemplo, que a Geometria foi um tema de suma importância para a Bauhaus (DROSTE, 2018).

Conforme pode-se verificar, a Geometria está presente, de forma mais ou menos explícita, nos diversos documentos vinculados ao MEC, em todas etapas da Educação Básica e, também, no Ensino Superior em Design. Mediante tal evidência, a reflexão sobre o desenvolvimento de competências e habilidades relacionadas à Geometria na formação de designers se mostra extremamente pertinente e necessária.

\section{A Geometria no curso de Design da FAU USP}

Respeitadas as DCND, cada curso de graduação tem a liberdade de desenvolver seu PPC (ou Projeto Político Pedagógico - PPP), em consonância com os Projetos Pedagógicos Institucionais (PPI) e os Planos de Desenvolvimento Institucional (PDI), de tal forma que sejam adequados às realidades em que as IES são conformadas.

De acordo com o PPC Design USP, aprovado em 2017 e implantado em 2018, não consta uma disciplina que tenha em seu título a palavra "Geometria". O Currículo vigente até 2017 possuía uma disciplina intitulada "Geometria projetiva" (AUT2502), que contava com uma carga horária de 30 horas. Na nova matriz curricular, essa disciplina foi substituída pela disciplina equivalente intitulada "Técnicas de visualização e representação I", também oferecida pelo Departamento de Tecnologia da Arquitetura (AUT), estruturada com uma carga horária total de 60 horas, distribuídas em 30 horas de aula e 30 horas de trabalho.

A disciplina "Técnicas de visualização e representação I" é uma disciplina obrigatória, oferecida no primeiro semestre do curso. Portanto, trata-se de uma disciplina considerada de 
fundamentação e de "caráter propedêutico", visando à preparação das "bases para processos pedagógicos posteriores" (USP, 2017, p. 5). De acordo com o PPC Design USP, "a estrutura curricular apresenta, nos quatro primeiros semestres ( $1^{\circ}$ e $2^{\circ}$ ano), as fundamentações teóricas e práticas que buscam a formação de repertório e vocabulário próprios, e o domínio da representação técnica" (USP, 2017, p. 5).

Também, em consonância com as DCND, essa disciplina pertence ao eixo de conteúdos básicos, que engloba o

estudo da história e das teorias do Design em seus contextos sociológicos, antropológicos, psicológicos e artísticos, abrangendo métodos e técnicas de projetos, meios de representação, comunicação e informação, estudos das relações usuário/objeto/meio ambiente, estudo de materiais, processos, gestão e outras relações com a produção e o mercado (BRASIL, 2004, p. 2; USP, 2017, p. 5).

Essa disciplina possui como objetivo:

Desenvolver a representação através do desenho à mão livre e instrumentado. Estudar os objetos e suas variações formais em pranchas com detalhes, vistas e perspectivas. Propiciar, de modo sistêmico, o desenvolvimento da capacidade de organizar o raciocínio geométrico-espacial do esboço à representação gráfica normatizada. Desenhar com propriedade utilizando-se de elementos de composição, proporção e Verdadeira Grandeza (VG) (USP, 2017, p. 30, grifos nossos).

Dentre os tópicos que compõem o programa dessa disciplina, estão "Geometria Descritiva principais conceitos" e "Planificação de formas - sólidos geométricos", os quais trazem explicitamente temas relacionados à Geometria. Também são contempladas questões relativas aos "Desenhos com Vistas Ortográficas e Perspectiva Isométrica no $1^{\circ}$ Diedro" e "Perspectiva Cavaleira / Perspectiva Explodida" (USP, 2017, p. 30), os quais, de certa forma pertencem ao universo da Geometria.

Também há, na matriz do curso, uma disciplina obrigatória intitulada "Técnicas de Visualização e Representação II", a qual tem por objetivo, igualmente a outra disciplina homônima, "propiciar, de modo sistêmico, o desenvolvimento da capacidade de organizar o raciocínio geométrico-espacial" (USP, 2017, p. 46), entretanto, valendo-se da "representação através da modelagem digital". Como se vê, os saberes geométricos são abordados tanto a partir da utilização de técnicas tradicionais de desenho quanto com o auxílio de computador.

Na nova matriz, além dessas, outras seis disciplinas apresentam, em sua lista de bibliografia, pelo menos, um título relacionado à Geometria, tal como o livro intitulado "Geometria do Design: estudos sobre proporção e composição" (ELAM, 2001). No entanto, percebe-se uma redução da abordagem explícita da Geometria nesta matriz curricular, se comparada à anterior. Este novo contexto exige uma reflexão sobre a postura a ser adotada em relação ao conteúdo da Geometria tanto nas PHE - caso elas voltem a ser aplicadas na USP - quanto no âmbito das disciplinas, de tal forma que as habilidades e competências geométricas necessárias ao exercício da profissão de designer sejam garantidas aos graduandos. 


\section{Geometria nas PHE da FAU USP: os saberes geométricos como pré-requisitos para ingresso no curso de Design}

Na USP, até 2016, as PHE eram compostas por provas que se subdividiam em: (1) geometria (e funções), (2) linguagem (desenho) bidimensional e (3) linguagem tridimensional. Nesse sentido, os conteúdos de Geometria ganhavam uma considerável relevância, de tal forma que uma das provas era especificamente sobre os conteúdos desse campo (UNIVERSIDADE DE SÃO PAULO, [2017]).

De acordo com as informações contidas na Prova de Geometria do vestibular 2016, essa prova visava a "avaliar o potencial do candidato quanto ao entendimento e representação do espaço" (FUNDAÇÃO UNIVERSITÁRIA PARA O VESTIBULAR, 2015, p.1). Destaca-se que, dentre os conteúdos avaliados nas provas de Geometria (e funções) que compuseram as PHE para ingresso no curso de Design da USP entre 2006 e 2016, estão "concordância e tangência" - conteúdos que, dada a limitação da extensão deste texto, tomaremos como representativos de Geometria das PHE neste artigo.

À guisa de exemplificação, podem ser mencionadas a primeira questão da prova de 2016 e a primeira questão da prova de 2006 (Figura 1).
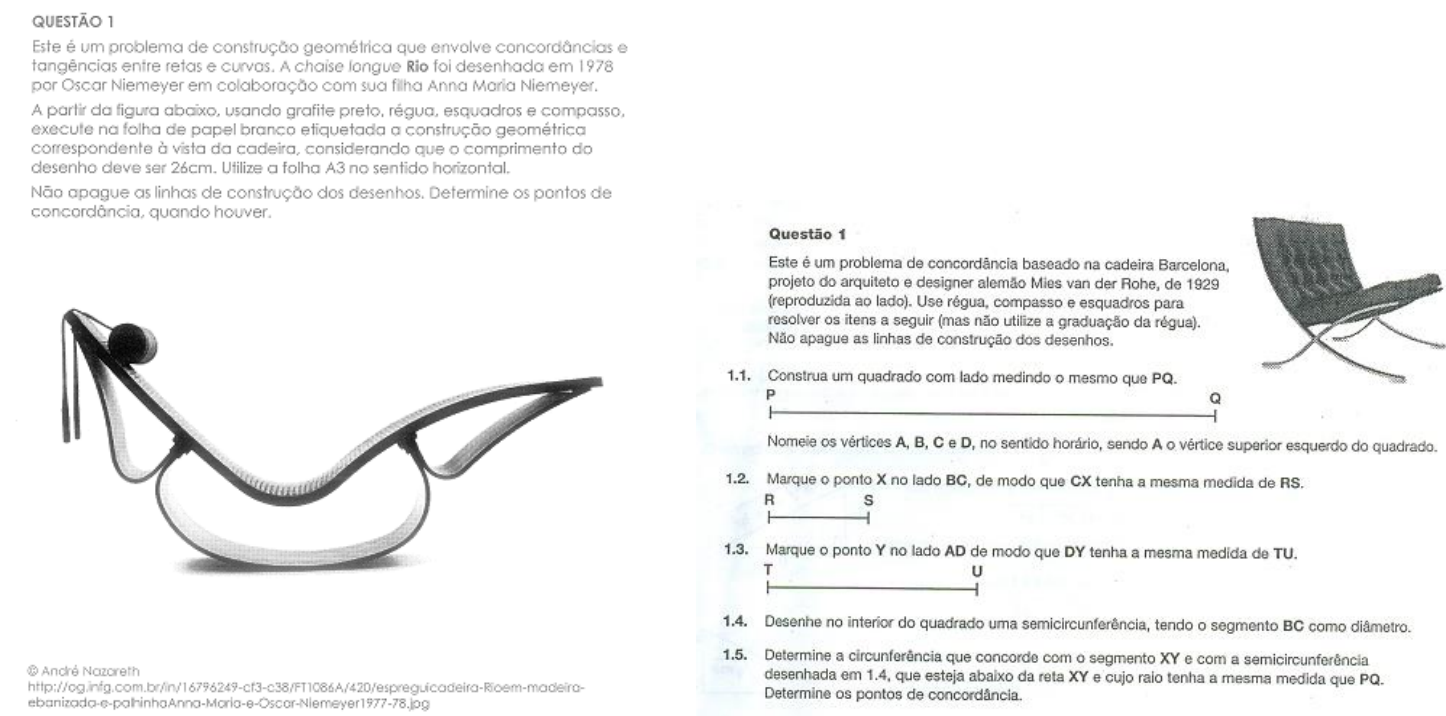

Figura 1: Questões sobre concordâncias das provas de Geometria (e funções) de 2016 (à esquerda) e 2006 (à direita). Fontes: Fundação Universitária para o Vestibular (2015, p. 2) e Fundação Universitária para o Vestibular (2005, p. 1).

Essas duas questões são muito semelhantes, tanto do ponto de vista do conteúdo a ser avaliado, quanto do ponto de vista da forma do enunciado. Elas partem de um objeto de design (em 2006, tratava-se da cadeira Barcelona, de Mies van der Rohe, e, em 2016, foi apresentada a chaise longue Rio, de Oscar Niemeyer e Anna Maria Niemeyer) e exploram um tópico da construção geométrica que envolve concordâncias e tangências entre retas e curvas.

Em ambas as questões, os avaliadores solicitavam que, com a utilização de instrumentos de desenho, tais como régua, esquadros e compasso, os candidatos resolvessem graficamente o problema dado, deixando evidentes as linhas de construção. Esse é um procedimento comum a todas as provas, uma vez que, como é de se supor, os avaliadores, para além da resposta final, avaliavam o processo de solução do problema. 
Essa é a mesma lógica da quarta questão da prova de 2011 e da primeira questão da prova de 2013, as quais partem de construções gráficas bidimensionais para a proposição de um problema relativo à tangência e concordância entre arcos de circunferências.

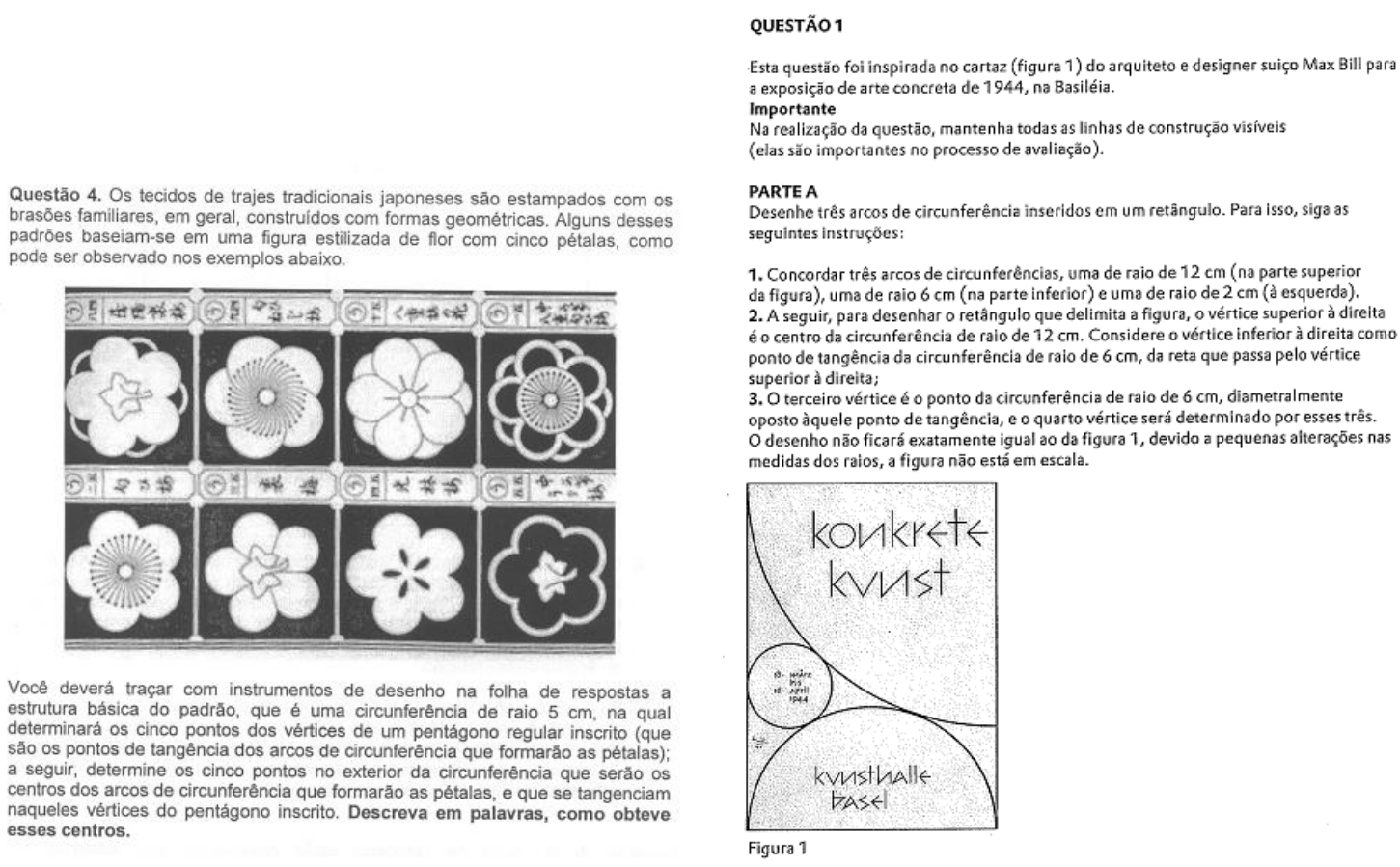

Figura 2: Questões sobre concordâncias das provas de Geometria e funções de 2011 (à esquerda) e 2013 (à direita). Fontes: Fundação Universitária para o Vestibular (2010, p. 4) e Fundação Universitária para o Vestibular (2012, p. 2).

Embora diversas questões partam de um produto do design, conforme supracitado, há algumas que não apresentam nenhuma imagem a partir da qual o enunciado é construído, exigindo dos candidatos tanto a interpretação do texto, quanto a transição de uma representação dada em língua natural (linguagem verbal) para uma representação geométrica (linguagem gráfica), importante habilidade em Geometria, relacionada à visualização/abstração. Esse é o caso, por exemplo, da primeira questão da prova de 2015 (Figura 3).

\section{QUESTÃO 1}

Construa na folha de respostas, com régua e compasso, um pentágono regular de lado medindo 10 centímetros. Inscrever neste pentágono uma estrela de cinco pontas. Concorde cada par de arestas adjacentes da estrela, que fomem um ângulo obtuso entre si, com um arco de cirdunferência de raio 1 centímetro. Indique a construção dos centros e dos pontos de tangência desses arcos.

Deixe bem visíveis todas as linhas de construção, pois serāo avaliadas.

Figura 3: Questão sobre concordâncias da prova de Geometria e funções de 2015. Fonte: Fundação Universitária para o Vestibular (2014, p. 2).

Como se evidencia, a concordância entre arcos (e/ou retas) esteve muito presente nas PHE da FAU USP entre os anos de 2006 e 2016. Portanto, pode-se inferir que esse conteúdo seja de grande relevância na formação de designers. De fato, ao se olhar para os documentos relativos à Educação Básica e para os documentos vinculados à Educação Superior em Design, inclusive aqueles específicos da FAU USP, verifica-se que a Geometria se faz de alguma forma presente. 
A partir dessas análises, a despeito da relevância da Geometria para a atuação profissional dos designers, emergem algumas perguntas, de naturezas e ordens distintas, dentre as quais merecem ser citadas:

1. Por que a construção de arcos e circunferências se apresenta como um tópico relevante nas PHE da FAU USP? Tais problemas contribuem para "avaliar o potencial do candidato quanto ao entendimento e representação do espaço", conforme declarado no objetivo da prova?

2. Seria, de fato, a construção geométrica de arcos e circunferências, utilizando instrumentos de desenho, uma das habilidades demandadas para a formação de designers na contemporaneidade?

3. Considerando esse tópico como relevante para designers, os cursos de Design não deveriam incorporar em suas matrizes curriculares explicitamente esse conteúdo?

Tais questionamentos são tanto de caráter específico, restrito ao universo relativo à FAU USP, quanto de caráter geral, abrangendo questões mais profundas que dizem respeito aos processos avaliativos e ao desenvolvimento de competências e habilidades geométricas na formação de designers. Essas perguntas apontam para a necessidade de revisões permanentes dos conteúdos de Geometria, tanto na BNCC quanto nas DCND, bem como nos PPC e nas próprias PHE. Afinal, não se pode furtar às seguintes indagações: Para que ensinar Geometria nos dias de hoje? Quais são os conteúdos de Geometria que devem ser ensinados na Educação Básica? O que devem saber os designers em relação à Geometria? Além dessas perguntas, há que se refletir, ainda, sobre outras questões de fundo: Para que as PHE servem? O que as PHE avaliam?

À luz dos dados coletados e analisados, podem ser tecidas as considerações sobre os eixos temáticos apresentados no Memorando expedido pela presidente da Comissão de Graduação da FAU USP em 02 de maio de 2017 (UNIVERSIDADE DE SÃO PAULO, 2017), quando refletiu-se sobre a suspensão das PHE por um prazo de cinco anos na instituição:

1. Levando-se em conta as provas de Geometria das PHE da FAU USP, verifica-se que as questões não ultrapassam os conteúdos constantes na BNCC. Porém, há que se verificar se, de fato, essa base tem sido cumprida efetivamente pelas escolas, garantindo aos alunos o acesso a tais objetos de conhecimento e habilidades, o qual propicie condições equânimes de resolução das PHE, assegurando uma isonomia nos processos de seleção. Para a discussão deste tópico, contribuem diversos autores, dentre os quais vale destacar o artigo de Rabello (2005, p.49), o qual, já no início do século XXI, denunciava o "franco declínio" do ensino de desenho na Educação Básica no Brasil, a partir da década de 1970, repercutindo diretamente nos cursos superiores;

2. Quanto aos objetivos e finalidades das PHE, ainda há muitas incertezas e posições controversas. Seriam as PHE apenas mais um instrumento para redução do número de candidatos às vagas ofertadas pelas IES? Estariam as PHE a serviço de testar as habilidades específicas dos candidatos ou a sua aptidão para um determinado curso? Nesse caso, para além de uma definição precisa do rol de "habilidades específicas", a própria noção de "aptidão" merece reflexão. 
3. Há que se redefinir constantemente quais são os saberes (geométricos) mínimos (as competências e as habilidades mínimas) a partir dos quais se constroem os currículos dos cursos superiores. Assim, não parece fazer sentido avaliar, com as PHE, os conhecimentos dos alunos em determinados conteúdos, se os mesmos serão retomados em caráter básico (ou introdutório/propedêutico) no curso superior. Portanto, há que se pensar em diretrizes curriculares e em currículos mais precisos, além de inovadores e em pleno diálogo com as atribuições profissionais e com a realidade da Educação Básica brasileira.

\section{Considerações Finais}

Este artigo procurou refletir, a partir de análises documentais vinculados à Educação Básica e Superior, tomando as PHE da FAU USP como objetos empíricos, sobre a participação da Geometria na formação dos designers no Brasil.

Por não haver muitas pesquisas sistematizadas sobre a aplicação das PHE em Design, esta pesquisa suscitou muito mais perguntas do que respostas, sinalizando importantes aspectos que merecem discussões aprofundadas. À guisa de considerações finais, a partir de uma retomada da problemática tratada neste artigo e dos resultados alcançados com a pesquisa, sobretudo ao se considerar as questões pertinentes ao ensino da Geometria, merecem ser evidenciados dois apontamentos principais:

1. Os tópicos relacionados à Geometria plana e à construção geométrica, em especial "concordância e tangência", têm estado presente com muita frequência nas PHE para o curso de Design da USP. Conforme demonstrado, das 39 questões presentes nas provas de 2006 a 2016, 12 eram sobre concordância e tangência. No entanto, ao que diz respeito a essas provas em geral, há que se questionar sobre sua validade, forma o conteúdo, uma vez que, assim como as provas dos vestibulares e do Enem, as PHE têm funcionado, paradoxalmente, ora como uma barreira e ora como uma ponte que se interpõe entre diversos candidatos e os cursos de graduação por eles almejados;

2. Há também que se ponderar sobre as reais habilidades vinculadas às diferentes áreas do conhecimento exigidas dos candidatos aos cursos de Design, em especial àquelas pertencentes à Geometria (construção e desenho geométricos), bem como sobre os currículos dos cursos, os quais têm por finalidade elencar conhecimentos necessários para o desenvolvimento de competências e habilidades demandas para os designers. Essas questões, de forma dialética, devem levar em consideração o status quo da BNCC e das DCND, fomentando possíveis alterações.

Por fim, mediante tantas inquietações suscitadas neste artigo, espera-se contribuir, de forma mais ampla, para a discussão sobre os saberes geométricos como componentes curriculares dos cursos de Design e como pré-requisito para os ingressantes no Ensino Superior no Brasil, sobretudo em cursos de Design. 


\section{Referências}

BARDIN, Laurence. Análise de conteúdo. São Paulo: Edições 70, 2011.

BRASIL. Casa Civil. Lei n. 9.394, de 20 de dezembro de 1996. [2019]. Disponível em: <http://www.planalto.gov.br/ccivil_03/Leis/L9394.htm>. Acesso em: 4 abr. 2019.

BRASIL. Ministério da Educação. Base nacional comum curricular. [2017]. Disponível em: <encurtador.com.br/bmpqG>. Acesso em: 5 jan. 2019.

BRASIL. Ministério da Educação. Base nacional comum curricular: Ensino Médio. [2018]. Disponível em: <http://portal.mec.gov.br/index.php?option=com_docman\&view=download\&alias=85121bncc-ensino-medio\&category_slug=abril-2018-pdf\&Itemid=30192>. Acesso em: 5 jan. 2019.

BRASIL. Ministério da Educação. Diretrizes curriculares nacionais gerais da Educação Básica. Brasília: MEC/SEB/DICEI, 2013. Disponível em: <http://portal.mec.gov.br/docman/julho-2013-pdf/13677-diretrizes-educacao-basica-2013pdf/file >. Acesso em: 5 mar. 2019.

BRASIL. Ministério da Educação. Parâmetros curriculares nacionais: Matemática. Brasília: MEC/SEF, $1997 . \quad$ Disponível em: <https://cptstatic.s3.amazonaws.com/pdf/cpt/pcn/volume-03-matematica.pdf >. Acesso em: 5 fev. 2019.

BRASIL. Ministério da Educação. Parâmetros curriculares nacionais Ensino Médio: Parte III Ciências da Natureza, Matemática e suas Tecnologias. Brasília: MEC, [1999]. Disponível em: <http://portal.mec.gov.br/seb/arquivos/pdf/ciencian.pdf>. Acesso em: 5 fev. 2019.

BRASIL. Ministério da Educação. PCN Ensino Médio +: orientações educacionais complementares aos Parâmetros curriculares nacionais: Ciências da Natureza, Matemática e suas tecnologias. [2002]. Disponível em: <http://portal.mec.gov.br/seb/arquivos/pdf/CienciasNatureza.pdf〉. Acesso em: 5 mar. 2019.

BRASIL. Ministério da Educação. Referencial curricular nacional para a Educação Infantil. Brasília: MEC/SEF, 1998. v.3. Disponível em: <http://portal.mec.gov.br/seb/arquivos/pdf/volume3.pdf >. Acesso em: 5 fev. 2019.

BRASIL. Ministério da Educação. Resolução no 5 , de 8 de março de 2004. Brasília: MEC, 2004. Disponível em: < http://portal.mec.gov.br/cne/arquivos/pdf/rces05_04.pdf>. Acesso em: 1 mar. 2019.

BRASIL. Ministério da Educação. SISU: Sistema de seleção unificada. Brasília: MEC, 2019. Disponível em: <http://www.sisu.mec.gov.br>. Acesso em: 1 mar. 2019.

CERQUEIRA, Daniel Lemos. Teste de habilidades específicas em Música: um relato de experiência. Revista Música e Linguagem, v.1, n. 4, p. 17-36., ago. 2015.

DROSTE, Magdalena. Bauhaus. 2. ed. [S.1.]: Taschen, 2018.

ELAM, Kimberly. Geometry of Design: studies in proportion and composition. New York, Princeton Architectural Press, 2001.

FOLHA DE SÃO PAULO. RUF - Ranking Universitário Folha 2018: Arquitetura e Urbanismo. 2018. Disponível em: <https://ruf.folha.uol.com.br/2018/ranking-decursos/arquitetura-e-urbanismo/>. Acesso em: 5 mar. 2019.

FUNDAÇÃO UNIVERSITÁRIA PARA O VESTIBULAR. FUVEST 2006: Prova de Geometria e funções. São Paulo: FUVEST, 2005. 
FUNDAÇÃO UNIVERSITÁRIA PARA O VESTIBULAR. FUVEST 2011: Prova de Geometria e funções. São Paulo: FUVEST, 2010.

FUNDAÇÃO UNIVERSITÁRIA PARA O VESTIBULAR. FUVEST 2013: Prova de Geometria e funções. São Paulo: FUVEST, 2012.

FUNDAÇÃO UNIVERSITÁRIA PARA O VESTIBULAR. FUVEST 2015: Prova de Geometria e funções. São Paulo: FUVEST, 2014.

FUNDAÇÃO UNIVERSITÁRIA PARA O VESTIBULAR. FUVEST 2016: Prova de Geometria. São Paulo: FUVEST, 2015.

RABELLO, Paulo Sérgio Brunner. Ensino de Geometria Descritiva no Brasil. Revista Ciência Hoje, v. 37, nov. 2005, p. 49 - 51.

TESTE de habilidades específicas (THE): como estudar? [s.d.]. Disponível em: <http://voupassar.club/teste-de-habilidades-especificas-como-estudar/>. Acesso em: $10 \mathrm{abr}$. 2019.

UNIVERSIDADE DE SÃO PAULO. Faculdade de Arquitetura e Urbanismo. Design. [s.d.]. Disponível em: <http://www.fau.usp.br/graduacao/design/>. Acesso em: 1 mar. 2019.

UNIVERSIDADE DE SÃO PAULO. Faculdade de Arquitetura e Urbanismo. MEMO.CG014/FAU/2017. São Paulo: USP, 2017. Disponível em: <http://www.cg.fau.usp.br/Documentos/2017/DECISAO\%20FAU_Suspensao\%20das\%20pr ovas\%20de\%20habilidades\%20especificas.pdf>. Acesso em: 10 fev. 2019.

UNIVERSIDADE DE SÃO PAULO. Faculdade de Arquitetura e Urbanismo. Curso de Design: projeto pedagógico. São Paulo: USP, 2017. Disponível em: $\langle$ http://www.fau.usp.br/arquivos/acad/NOVO_PPP_Design_de_2018.pdf $>$. Acesso em: 5 fev. 2019.

UNIVERSIDADE DE SÃO PAULO. Faculdade de Arquitetura e Urbanismo. Vestibular. [2017]. Disponível em: 〈http://www.cg.fau.usp.br/Vestibular.asp>. Acesso em: 20 fev. 2019.

\section{Sobre os autores}

Frederico Braida é bacharel em Arquitetura e Urbanismo pela Universidade Federal de Juiz de Fora, onde atua como professor na graduação e na pós-graduação. Mestre em Urbanismo pela Universidade Federal do Rio de Janeiro. Mestre, Doutor e Pós-Doutor em Design pela Pontifícia Universidade Católica do Rio de Janeiro. Atualmente está lotado na Universidade Tecnológica Federal do Paraná, onde também realiza um pós-doutorado em Matemática.

frederico.braida@ufjf.edu.br

Rodolfo Eduardo Vertuan é licenciado em Matemática, especialista em Educação Matemática, mestre e doutor em Ensino de Ciências e Educação Matemática pela Universidade Estadual de Londrina. Atualmente é professor adjunto da Universidade Tecnológica Federal do Paraná, onde atua na graduação, pós-graduação e como Diretor-Geral do Câmpus Toledo. Também exerce a função de diretor da regional Paraná da Sociedade Brasileira de Educação Matemática. rodolfovertuan@utfpr.edu.br

Rodrigo Manoel Dias Andrade é bacharel e mestre em Matemática pelo Instituto de Biociências, Letras e Ciências Exatas da UNESP. Doutor em Matemática Aplicada pelo Instituto de Matemática e Estatística da Universidade de São Paulo. Atualmente é professor adjunto da Universidade Tecnológica Federal do Paraná e coordena o Mestrado Profissional em Matemática em Rede Nacional (PROFMAT) nesta instituição.

rodrigomandrade@utfpr.edu.br 